\title{
Place-based taste: geography as a starting point for deliciousness
}

\author{
Joshua Evans ${ }^{1}$, Roberto Flore ${ }^{1}$, Jonas Astrup Pedersen ${ }^{1}$ and Michael Bom Frøst ${ }^{1,2^{*}}$
}

\begin{abstract}
Nordic Food Lab (NFL) is a non-profit, open-source organisation that investigates food diversity and deliciousness. We combine scientific and cultural approaches with culinary techniques from around the world to explore the edible potential of the Nordic region. We are intent on broadening our taste, generating and adapting practical ideas and methods for those who make food and those who enjoy eating. This paper describes some of our methods, using geography as a starting point for the exploration of deliciousness, exemplified in our lunch menu served at the Science of Taste symposium in Copenhagen in August 2014.
\end{abstract}

Keywords: Deliciousness, Geography, Food diversity, Food systems, Nordic region, Food design, Theoretical framework

\section{Introduction}

In November 2004, a symposium for Nordic cuisine was organised in Copenhagen at the then newly opened Nordatlantens Brygge, a cultural house for the North Atlantic parts of the Nordic region. Here a group of chefs and food professionals created a manifesto for a new Nordic cuisine that was signed by chefs from Denmark, Faroe Islands, Finland, Greenland, Norway, Sweden and Åland [1]. The symposium and manifesto crystallised a new Nordic food movement that has since developed the regional cuisines of the Nordic countries and territories beyond what anyone could have imagined.

Nordic Food Lab was founded in 2008 in the same spirit, as a research and development lab with the purpose of exploring food in the Nordic region. Chef René Redzepi and gastronomic entrepreneur Claus Meyer, coowners of the restaurant Noma in Copenhagen, realised that this investigation could not be undertaken in the restaurant kitchen alone. They saw a need for a space where chefs, scientists, and other researchers could come together to investigate raw materials, traditional processes, and modern techniques more deeply than the pressure of daily service would allow. The outcome of the lab's activities was directed primarily towards the development of

\footnotetext{
* Correspondence: mbf@nordicfoodlab.org

${ }^{1}$ Nordic Food Lab, Department of Food Science, University of Copenhagen,

Rolighedsvej 30, DK-1958 Frederiksberg C, Denmark

${ }^{2}$ Sensory Science Group, Department of Food Science, University of

Copenhagen, Rolighedsvej 30, DK-1958 Frederiksberg C, Denmark
}

restaurants, but also with the purpose of expanding knowledge in academic and applied contexts.

Since then, Nordic Food Lab (NFL) has helped to bring science and gastronomy closer together in Denmark [2]. Over the years, we have attempted to shift how chefs and scientists work together, from a simple one-way process of chefs asking scientists to help troubleshoot and solve immediate problems in the kitchen, to a more collaborative effort where research questions are developed and investigated together, integrating different methods and types of expertise. One good example is the work by Mouritsen et al. [3], which explored the use of seaweeds in a Nordic culinary context, and demonstrated how the seaweeds sugar kelp and in particular dulse have great potential as ingredients in the new Nordic cuisine to provide flavour and umami. The interests of the chefs and scientists are diverse and none are experts outside their respective fields, so a true collaborative work brings all parties further than any of them would have managed alone.

The experimental methods used at NFL often resemble those of a design studio with iterations of recipes and as thorough an exploration as possible of the sensory space a particular food can occupy [4]. For this reason, we rely on team members who are capable of dismantling the unnecessary division between science and craft, drawing on knowledge from natural sciences, the humanities and the vast world of diverse culinary traditions. 
Diversity is both our starting point and our goal. It forms a loop of feedback mediated by ecology, necessity, and appetite. There is no single food that can nourish us on its own. The pursuit of good food runs parallel with the pursuit of the biological and cultural diversity upon which truly sustainable food systems rely. Yet infinite choice can be paralysing, and we find creative and investigative freedom in the geographical constraint of our base of our raw materials.

\section{Theoretical framework for deliciousness}

In order to create delicious food, it is useful to understand the principles for perception of food and the evaluation of goodness in a food. Creating a new dish or finding a new ingredient to use in our cuisine bears similarities to how we interact with other artefacts of human culture. Looking to theories of human affective response to designed objects or artefacts can thus provide a useful perspective on how similar processes play out in the kitchen and laboratory. Desmet and Hekkert [5] argue that the affective response to a product is a function of three components. First is the immediate perception through our senses, what have previously been termed as the aesthetic experience [6]. Second is the experience of meaning that we ascribe through interpretation and association to assess the personal or symbolic significance of a product experience. The third component in our product experience is the emotional experience that arises from an evaluation of the significance that an experience has for the individual's well-being.

A theory for our interaction with food also needs to take into account the function that food serves for us, the relief of hunger, and the nutritional requirements of our bodies. Norman [7] has formulated that we interact with an object at three distinct levels: First, there is the visceral level, the immediate sensory level. It is how our perception is shaped through the hardwiring of our sensory systems. Second, there is the behavioural level, the function that our interaction with an object serves, such as the needs it satisfies for us. In relation to food, the functional level is the food safety and nutritional aspects, the absence of harmful substances or organisms and the provision of beneficial and necessary nutrients. Third, Norman [7] uses the term 'reflective level' to describe the overall impact a product or object has based on the meaning it gives to us, similar to the meaning level described above by Hekkert and Leder [5]. Figure 1 outlines our interpretation of the three levels of interaction with a food. Here we classify our interaction with food at three overall levels: immediately through our senses, the function the food has, and the reflections we have on the creation of the food.

\section{Perceptual level}

We appreciate certain tastes from birth (sweet, fatty, and umami [8]) because they signal the presence of available

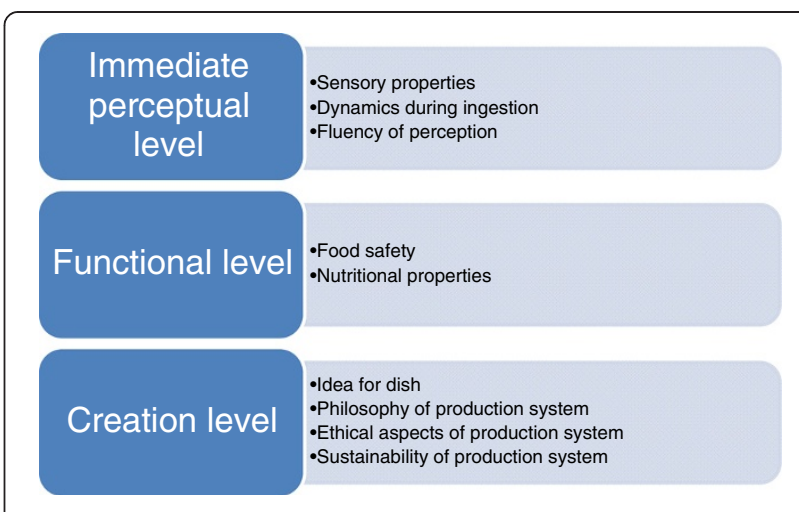

Figure 1 Schematic overview of three levels of food interaction. Overview of requirements for a food to be considered 'good' in different domains.

energy. Appreciation of other sensory properties such crunchy [9] or creamy [10] is learned from positive consequences through conditioned learning and association [11]. Some sensory properties are more dynamic, and their appreciation is a result of the sensory arc that occurs during ingestion, as we chew and swallow. The main purpose of chewing is to comminute, lubricate and subsequently form food into a bolus that can be swallowed without negative consequences, such as inhalation of small particles into the lower respiratory tract [12]. The success of a food from an oral manipulation point of view depends on the efficiency of comminution, lubrication, and bolus formation. The trajectory of this process has been termed the philosophy of the breakdown path [13].

When we experience foods we implicitly learn some lawful relationship between different sensory properties. For example, we learn to associate the bright orange colour of sea buckthorn with its passion fruit-like aroma and its tangy sourness. After repeated exposures there is fluency in this learnt relationship, which generates intrinsic pleasure as a result of this faster perceptual processing [6]. Gradually, as we become more experienced, our sensory systems can better discern small differences and nuances that in earlier exposures went unnoticed. Gibson [14] suggests that the perceptual development and learning are processes of distinguishing the features of an almost inexhaustibly rich input, hinting at the immense potential to continually develop our senses further. Experienced wine connoisseurs, for example, may be able to distinguish minuscule differences in sensory properties that allow them to correctly identify the vineyard, producer and vintage of a wine and to take great pleasure in analysing and dissecting these sensory inputs of a food.

\section{Functional level}

The function of food from a physiological perspective should not be neglected, although it is something that is often taken for granted. Food needs to be safe to eat, i.e. 
not cause disease. A good food serves the purpose of providing nourishment, and indeed, the range of intake that provides a person with sufficient macro- and micronutrients is broad. And though nutritional recommendations should be seen as guidelines that can form the basis for nutrition policies, or formulation of diets and foods [15], they are not the be-all and end-all of the complex functionality of food in diets in practice.

\section{Creation level}

In relation to food, the parallel to the reflective level or the meaning we ascribe to food is their creation - the production system that brings about the food, or the ideas behind a particular food or dish. A particularly good example of a food that is admired for its idea is Michel Bras' 'chocolat coulant', or chocolate cake with a runny heart that the chef invented in the early 1980s, which for many years has been a signature dish in his restaurant. According to chefs, it is one of the most copied recipes in the world. The ingenuity that was necessary for Michel Bras to develop this particular cake, with a complex preparation that according to legend includes short pieces of a garden hose and freezing the dough before baking, has made it appreciated by his diners for decades, and admired by chefs all over the world. It has helped build Michel Bras' reputation as one of the best chefs in the world (see for instance [16]). Similarly, the artist Olafur Eliasson expresses his admiration for René Redzepi's dish 'Milk skin with Grass', where the grass and the garnishes all originate from the same pasture as the cow that made the milk, and upon which it grazed on, a representation of a particular place at a particular time [17].

A significant part of the appreciation for a food can stem from how it has been created. Several organisations have developed guidelines for goodness in the production system according to their principles. The International Federation of Organic Agriculture Movements (IFOAM) has a set of four principles that form a base for interconnected ethical principles to guide the development of organic agriculture. The four principles are briefly put: health, ecology, fairness and care [18]. The Slow Food movement has a similar succinct statement for their manifesto for good food: good, clean and fair $[19,20]$. The principles for both these organisations can also be understood in terms of philosophy, ethics and sustainability, as indicated in Figure 1.

These three levels of interaction with a food-perceptual, functional, and creational-help us understand the underlying principles for delicious foods, and can offer explanations for why some foods are indeed delicious.

\section{The menu}

Food that excels in the three different domains at the same time is irresistible, as the goodness in the different domains act in synergy with each other. Our pursuit of deliciousness leads us to seek out the delicious potential in as many places and organisms as possible, and often, it is in the neglected, underutilised, forgotten and ignored raw materials that we discover and rediscover unique sources of deliciousness. Similarly, our interest in exploring culinary techniques from both our region and cultures across the world allows us to broaden the culinary potential of these raw materials, by tracing the connections between diverse traditions and translating existing knowledge into our regional context. Combining this biogeographical constraint for raw materials with an openness to all types of knowledge and technique is a starting point for cooking that says something about us and imbues the foods we eat with a connection to this place and this time.

For the Science of Taste symposium, our team developed a menu to both nourish the symposium participants and illustrate how food can be delicious in more than one way. The menu consisted of four dishes served in succession. Figure 2 shows a gallery of images of the different elements of the menu.

\section{Beef heart tartare}

We wanted to illustrate the particular qualities of (what are nowadays) underutilised parts of the animal. The heart is a continuously working muscle, which gives it a very different texture than skeletal muscles. Our hearts came from 1-year-old biodynamic calves from Østagergård in Jystrup, Denmark, which we minced while maintaining some structure of the meat. We seasoned the minced heart with black garlic, fresh tarragon, and fig leaf tincture. Black garlic is a product originating in East Asia, and is produced by keeping garlic in a warm environment with little airflow for around 60 days (we seal ours in vacuum bags and keep them at $60^{\circ} \mathrm{C}$ ) [21]. This process denatures the alliinase enzyme responsible for transforming nonvolatile alliin into volatile allicin, the pungent sulphurous compound in garlic, especially when its cells are ruptured. Moreover, the low but steady heat creates cascades of low-temperature Maillard reactions, although at a much slower rate than the Maillard reactions commonly experienced in cooking. The finished garlic is characterised by a deep black colour and complex caramelised fragrances.

The tarragon was grown biodynamically at Kiselgården in Ugerløse, Denmark, and provided the freshness to complement the dark richness and acidity of the black garlic.

The Danish island of Bornholm, between Sweden, Germany and Poland at the mouth of the Baltic Sea, has a unique microclimate along its southern coast: soft beaches of fine white sand and an exceptional warmth that lasts later into the fall than is characteristic of the region. This microclimate gives rise to a particular ecology, which includes a robust population of fig trees. In the summer, we made a tincture-a strong infusion of 

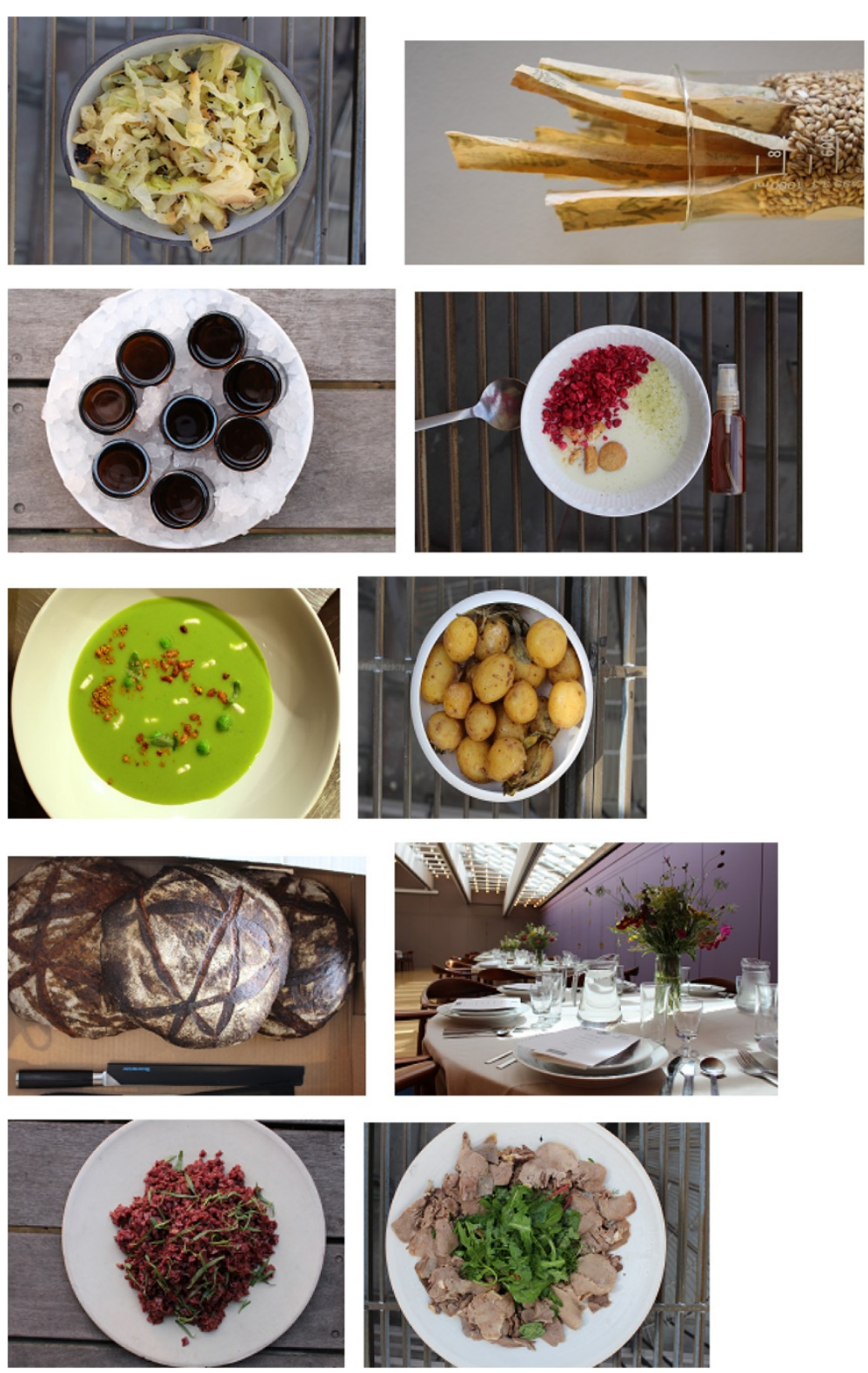

Figure 2 Gallery of the different elements of the menu. Layout of the tables, crispbread, gin, Peas ' $n$ ' Bees, sourdough bread, tongue and koji-chovies, potatoes, cabbage, and koldskål.

high-proof ethanol, which has both gastronomic and medicinal applications-from some of these fig leaves, yielding a concentrated source of their characteristic aroma: part coconut and part coumarin (the sweetsmelling compound in tonka bean, woodruff, and sweet clover, among others). A small amount of tincture provided complex herbal top notes, binding the dish together.

We served the dish with a crispbread laminated with wild mugwort and beach roses, and a chilled shot of fragrant, woodsy gin from the island of Hven in the Øresund.

\section{Peas ' $n$ ' Bees}

This dish emerged from several sources of inspiration. In June 2014, some of our team visited the island of Livø in the Limfjord in northern Jutland to conduct fieldwork for our insect research. While on the island investigating the European cockchafer, we also obtained some fresh bee larvae from a local beekeeper, along with some very mature lovage stems from her garden. As part of an outdoor experimental cookout we steamed the delicate, fatty larvae inside the lovage stems along with jasmine flowers that at the time were riotously in bloom. The 
herbal and floral notes of the larvae were enhanced in this rustic and simple preparation, and we wanted to take it further in a more controlled context.

One of us (RF) was reminded of a traditional Italian dish that had a comeback in the 1970s called Risi e Bisi, or risotto with peas. The bee larvae visually reminded RF of the rice. The texture of the dish was enhanced with pearled barley boiled in lovage broth, to create a summery, roomtemperature soup of creamed fresh peas and lovage, with some blanched bee larvae, fried bee larvae, fresh lovage, and fermented bee pollen to garnish.

Bee larvae are often a waste product of organic beekeeping, as the drones are removed periodically throughout the summer months as a strategy to lower the Varroa mite population in the hive [22]. They also happen to be extremely nutritious-around $50 \%$ protein and $20 \%$ unsaturated fats-and their flavour, like honey, can vary according to the local flora and the time of year. All of this makes them a very exciting product to work with in the kitchen. The bee larvae we used in this dish were obtained from a beekeeper in Værløse, outside of Copenhagen, Denmark.

Along with this course, we served large sourdough loaves made with flour from Øland wheat, an old variety of wheat from the island of Øland in Sweden, and virgin butter-carefully cultured cream churned until just before the butterfat and buttermilk separate, yielding a foamy emulsion with a cloud-like texture and bright acidity.

\section{Tongue and koji-chovies}

Here again we wanted to showcase the delicious potential of another less-used cut. We cooked the tongues from the same calves (as used above) whole, sous vide for $4 \mathrm{~h}$ at $85^{\circ} \mathrm{C}$ with lots of aromatics. This was followed by $2 \mathrm{~h}$ more at $55^{\circ} \mathrm{C}$, with butter added. Then, we sliced them and served them slightly warm with lots of fresh greens and herbs and a bright herb sauce. To go along with the tongue, we boiled some new potatoes and tossed them in an umami-rich sauce of koji-chovies (herring fermented in the style of anchovies [23]) and halved pointy cabbage we had grilled and compressed with shio-koji (a mixture of koji, salt, and water, with powerful enzymatic activity) to break it down and bring out its natural sweetness. Both the koji-chovies and shio-koji are excellent examples of translation of technique from other culinary traditions, taking our love of cured anchovies and applying it to a common small fish of the Nordic region, for example, or using the versatility of koji, grain fermented with the fungus Aspergillus oryzae, to enhance our fermentation techniques and other processes [24]. The koji, made mainly on rice in East Asia, produces amylases which saccharify the starches allowing the substrate to be further fermented into alcohol (as is the case with sake, or rice wine), along with proteases and lipases which can be further used to break down proteins into amino acids and fats into fatty acids. The enzymatic breakdown of proteins is the main mechanism that gives rise to umami taste in many products, such as soy sauce, miso, and their analogues around East and South-east Asia.

With the main course we served a juice made from Danish apples and seasoned lightly with juniper berries.

\section{Koldskål}

We finished with our take on a classic Danish summertime dessert-koldskål. It is a buttermilk soup with a base of egg yolk, traditionally aromatised with lemon zest and vanilla, and served with small cookies called 'kammerjunkere' and sometimes with fresh strawberries. In this version we opted for a more herbal profile, infusing the soup with lemon verbena, and serving with a mixture of freeze-dried lingonberries, raspberries and cranberries, and homemade kammerjunkere topped with lemon thyme sugar.

As this dish was served, we sprayed a finely misted tincture of birch buds over each table, a beautifully resinous and enveloping aroma from this underused part of the tree that conjures up forests of this most Nordic of trees.

We offered this variation on a beloved Danish classic to share the delicious Danish summer with our Danish and international guests alike.

\section{Competing interests}

The authors declare that they have no competing interests.

\section{Authors' contributions}

Josh Evans contributed to the writing and editing of the manuscript, and contributed to the development, creation and execution of the menu. Roberto Flore led the development, creation and execution of the menu, and reviewed the manuscript. Jonas Astrup Pedersen contributed to the development, creation and execution of the menu, and reviewed the manuscript. Michael Bom Frøst contributed to the writing and editing of the manuscript. All authors read and approved the final manuscript.

\section{Authors' information}

JE is the lead researcher at Nordic Food Lab, and has a background in the humanities. JE has worked extensively for the last years on food systems and sustainable agriculture. RF is the head chef at Nordic Food Lab. A trained chef, he has focussed in his career on building strong relationships between producers and chefs. JAP is a researcher and product developer at Nordic Food Lab, and has a background in food science, coupled with a longstanding interest in the culinary arts and the restaurant trade. MBF is the director for Nordic Food Lab and associate professor in Sensory Science at University of Copenhagen. He has a background in sensory science, and has worked extensively to connect science and culinary arts to the benefit of both.

\section{Acknowledgements}

This work has been funded by the following research and dissemination projects hosted at Nordic Food Lab: Smag for Livet (Taste for Life), a centre without walls that has focus on the taste of foods. (Smag for Livet is funded by the Nordea Foundation), and Discerning taste: creating the gastronomic argument for entomophagy, funded by the Velux Foundation. 
References

1. Ny Nordisk Mad: Köksmanifestet. [http://nynordiskmad.org/om-nnm-ii/ koeksmanifestet/]

2. Risbo J, Mouritsen OG, Frøst MB, Evans JD, Reade B: Culinary science in Denmark: molecular gastronomy and beyond. J Culin Sci Technol 2013, 11:111-130.

3. Mouritsen OG, Williams L, Bjerregaard R, Duelund L: Seaweeds for umami flavour in the New Nordic Cuisine. Flavour 2012, 1:4.

4. Evans JD: Non-Trivial Pursuit - New approaches to Nordic deliciousness. Anthropol Food 2012, S7. http://aof.revues.org/7262

5. Desmet P, Hekkert P: Framework of product experience. Int J Des 2007 1:57-66.

6. Hekkert $\mathrm{P}$, Leder $\mathrm{H}$, Aesthetics P: Product aesthetics. In Product Experience Edited by Schifferstein HNJ, Hekkert P. Amsterdam: Elsevier; 2008:259-285.

7. Norman DA: Emotional Design - Why We Love (or Hate) Everyday Things. New York, NY: Basic Books; 2004:257.

8. Ventura AK, Worobey J: Early influences on the development of food preferences. Curr Biol 2013, 23:R401-R408.

9. Szczesniak AS: Texture is a sensory property. Food Qual Prefer 2002, 13:215-225.

10. Frøst MB, Janhøj T: Understanding creaminess. Int Dairy J 2007, 17:1298-1311.

11. Prescott J: Chemosensory learning and flavour: perception, preference and intake. Physiol Behav 2012, 107:553-559.

12. Prinz JF, Lucas PW: An optimization model for mastication and swallowing in mammals. Proc Biol Sci 1997, 264:1715-1721.

13. Hutchings JB, Lillford PJ: The perception of food texture - the philosophy of the breakdown path. J Texture Stud 1988, 19:103-115.

14. Gibson JJ: The Senses Considered as Perceptual Systems. Boston: Houghton Mifflin; 1966.

15. Nordic Council of Ministers (Ed): Nordic Nutrition Recommendations 2012: Integrating Nutrition and Physical Activity. 5th edition. Copenhagen: Nordisk Ministerråd; 2012:627.

16. Bras M: Vivre la cuisine. In MAD food Symposium. 2011 [http://www. madfood.co/michel-bras/]

17. Eliasson O: Milk skin with grass. In Noma - Time and Place in Nordic Cuisine. Edited by Redzepi R. London: Phaidon; 2010:6-9.

18. Principles of Organic Agriculture. [http://www.ifoam.org/en/organiclandmarks/principles-organic-agriculture]

19. Slowfood - our philosophy. [http://www.slowfood.com/international/2/ourphilosophy]

20. Petrini C: Slow Food Nation. New York: Rizzoli Ex Libris; 2007

21. Evans JD: Black garlic. [http://nordicfoodlab.org/blog/2013/2/black-garlic]

22. Evans JD: The real reason we remove drone brood. [http://nordicfoodlab. org/blog/2012/12/the-real-reason-we-remove-drone-brood]

23. Reade B: Koji-chovy. [http://nordicfoodlab.org/blog/2013/6/koji-chovy]

24. Evans JD: Koji - history and process. [http://nordicfoodlab.org/blog/2013/ 8/koji-history-and-process]

doi:10.1186/2044-7248-4-7

Cite this article as: Evans et al:: Place-based taste: geography as a starting point for deliciousness. Flavour 2015 4:7.

\section{Submit your next manuscript to BioMed Central and take full advantage of:}

- Convenient online submission

- Thorough peer review

- No space constraints or color figure charges

- Immediate publication on acceptance

- Inclusion in PubMed, CAS, Scopus and Google Scholar

- Research which is freely available for redistribution 